\title{
Trophic transfer of organochlorine pesticides through food-chain in coastal marine ecosystem
}

\author{
Seung-Kyu $\operatorname{Kim}^{1,2^{+}}$ \\ ${ }^{1}$ Department of Marine Science, College of Natural Sciences, Incheon National University, Incheon 22012, Republic of Korea \\ ${ }^{2}$ Research Institute of Basic Sciences, Incheon National University, Incheon 22012, Republic of Korea
}

\begin{abstract}
The present study was designed to characterize the bioaccumulation of organochlorine pesticides (OCPs) in marine organisms (zooplankton, oyster, crab, and goby) on different trophic level. In the present study, sedentary bivalve (oyster) showed strong correlations in OCPs levels with surface sediment in the study area. This indicates the two compartments can be used as alternative for pollution monitoring of OCPs even in narrow scale in space. Bioaccumulation and trophic transfer of OCPs was strongly associated with their hydrophobicity (i.e., $\mathrm{K}_{\mathrm{OW}}$ ). $\mathrm{HCH}$ s with $\log \mathrm{K}_{\mathrm{OW}}<5$ did not show any enrichment through food-chain. However, log BAF values of OCPs with log $\mathrm{K}_{\mathrm{OW}}>5$ positioned over the 1:1 lines of $\log \mathrm{BAF}$ and $\log \mathrm{K}_{\mathrm{OW}}$ of the top predator, indicating the greater fugacities in the higher trophic level and thus the occurrence of biomagnification via ingestion. Based on trophic transfer factors (TTF), more hydrophobic OCPs with log $\mathrm{K}_{\mathrm{OW}}>5$ were enriched by several to several ten times in the highest trophic level relative to the lowest trophic level. This finding can be used in the establishment of marine environmental water quality criteria by considering biomagnification factors (TTF in this study) of OCPs.
\end{abstract}

Keywords: Bioaccumulation, Food-chain, Incheon North Harbor, $\mathrm{K}_{\mathrm{OW}}$, Organochlorine pesticides, Trophic level

\section{Introduction}

Organochlorine pesticides (OCPs) have been categorized to persistent organic pollutants (POPs) which is controlled under the international convention [1]. These OCPs, legacy POPs, have been considered to be well controlled and thus nearly phased out in real environment in Korea because their sale and use had been prohibited several ten years ago [2]. Recently, OCPs became a big issue in Korea because DDTs over environmental guideline were found in Korean poultry and soils. This social issue raises awareness of that OCP contamination is still unsolved in Korea.

The pollutants categorized in "POPs" represent that they are persistent, bioaccumulative, and toxic. Particularly, bioaccumulative property is an important factor when establishing environmental quality guideline as organism in higher trophic level including human can be exposed to enriched amount through food-chain [3-5]. Bioaccumulation means the phenomenon that body residue of pollutants exceeds the concentration in surrounding environment and occurs through all exposure routes including

This is an Open Access article distributed under the terms of the Creative Commons Attribution Non-Commercial License (http://creativecommons.org/licenses/by-nc/3.0/) which permits unrestricted non-commercial use, distribution, and reproduction in any medium, provided the original work is properly cited.

Copyright (C) 2020 Korean Society of Environmental Engineers respiration and diet ingestion [6-7]. As a special case, biomagnification means the enhancement of pollutants over the thermodynamic equilibrium with surrounding water in aquatic environment and is derived by ingesting contaminated diet [8]. Bioaccumulation and biomagnificaiton is a critical factor in establishing the environmental guideline such as water and sediment criteria. To identify the bioaccumulation and biomagnification of substances, several indices such as bioconcentration factor (BCF), bioaccumulation factor (BAF), and biomagnification factor (BMF) has been suggested [9].

In an earlier work of Kim et al. [10], the characteristics of OCP contamination of sediment and seawater were investigated in Incheon North Harbor basin, which was one of the most contaminated sites in Korea. The present work focuses on the contamination of biota and examines the occurrence of trophic transfer and its characteristics as influenced by main OCP uptake route, the presence/absence of superhydrophobicity in trophic transfer and bioaccumulation of OCPs, and the degree of bioaccumulation with respect to equilibrium with seawater. We investigated OCPs in selected marine species, including zooplankton (primarily

Received January 1, 2019 Accepted January 29, 2019

${ }^{\dagger}$ Corresponding author

Email: skkim@inu.ac.kr

Tel: +82-32-835-8862

ORCID: 0000-0002-1602-3288 
Paracalanus spp. and Acartia spp.), pacific oyster (Crassostrea gigas (C. gigas)), shore crab (Hemigrapsus penicillatus ( $H$. penicillatus)), and goby (Acanthogobius hasta (A. hasta)), to address these questions. These organisms were selected because they were plentiful and represent different trophic positions in the aquatic ecosystem.

\section{Materials and Methods}

\subsection{Study Area}

Incheon North Harbor is a part of the Kyeonggi Bay (Fig. 1). The details of the study area were described in a previous study [10]. In brief, the harbor has mainly supported anchoring for fishing and transport vessels as well as various industrial activities. The harbor basin with a total area of $5 \mathrm{~km}^{2}$ has a width of $1 \mathrm{~km}$ from inner to outer part of the harbor. A major water channel in the harbor basin, formed by by tidal currents and intermittent dredging operations, is connected with several tributary waterways for wastewater discharge. A wide tidal zone has been developed by high tidal range $(8-10 \mathrm{~m})$ in this area where its overall slope is less than $1 \%$. Strong semi-diurnal tidal currents $(1.2-2.3 \mathrm{~m} / \mathrm{s}$ and $0.9-1.9$ $\mathrm{m} / \mathrm{s}$ during neap tide and spring tide, respectively) run between Youngjong Island and the harbor. Seawater in the harbor basin flows to south during neap tide. Conversely, the spring tide flowing to north fills in the harbor basin.

Many environmental pollution sources have been in operation around the harbor area including a thermoelectric power plant in the north, an industrial complex including steel-manufacturers and pulp factories in the south, and a municipal wastewater treatment plant in the east. The wastewater treatment plant and the industrial complex discharge their wastewaters into the harbor basin through Gajwa Wastewater Storage Reservoir (GWSR) and Gajwa stream, respectively.

\subsection{Sample Collection}

The sampling locations for target marine organisms and seawater are shown in Fig. 1. The partitioning and spatial distribution characteristics of OCPs in abiotic media including surface sediment and suspended particulate matter were described in previous studies of the same study area $[11,12]$. So, the present study focusing on biotic media was also designed to validate and compare with the distribution features of OCPs in abiotic media.

Zooplankton samples (primarily Paracalanus spp. and Acartica spp.) were collected using a Bongo net with a 333- $\mu$ m mesh with horizontal tows for $10 \mathrm{~min}$ at 2 knots at inner and outer parts of the harbor (near W2, W3 and W4 in Fig. 1). After removing excess water via filtration through a $333-\mu \mathrm{m}$ mesh and centrifugation for $10 \mathrm{~min}$ at 1,500 rpm, the bulk samples were homogenized and analyzed. Oyster (C. gigas) as a filter-feeder, shore crab (H. penicillatus) as benthic feeder, and goby (A. hasta) as a pelagic feeder were collected with an iron chisel, by hand picking, and by fishing, respectively, near sites W2 and W3. All samples were collected in pre-cleaned amber glass jars or wrapped in combustion-cleaned aluminum foil, then immediately frozen and transported to the laboratory. Approximately $15 \mathrm{~g}$ of soft wet tissue

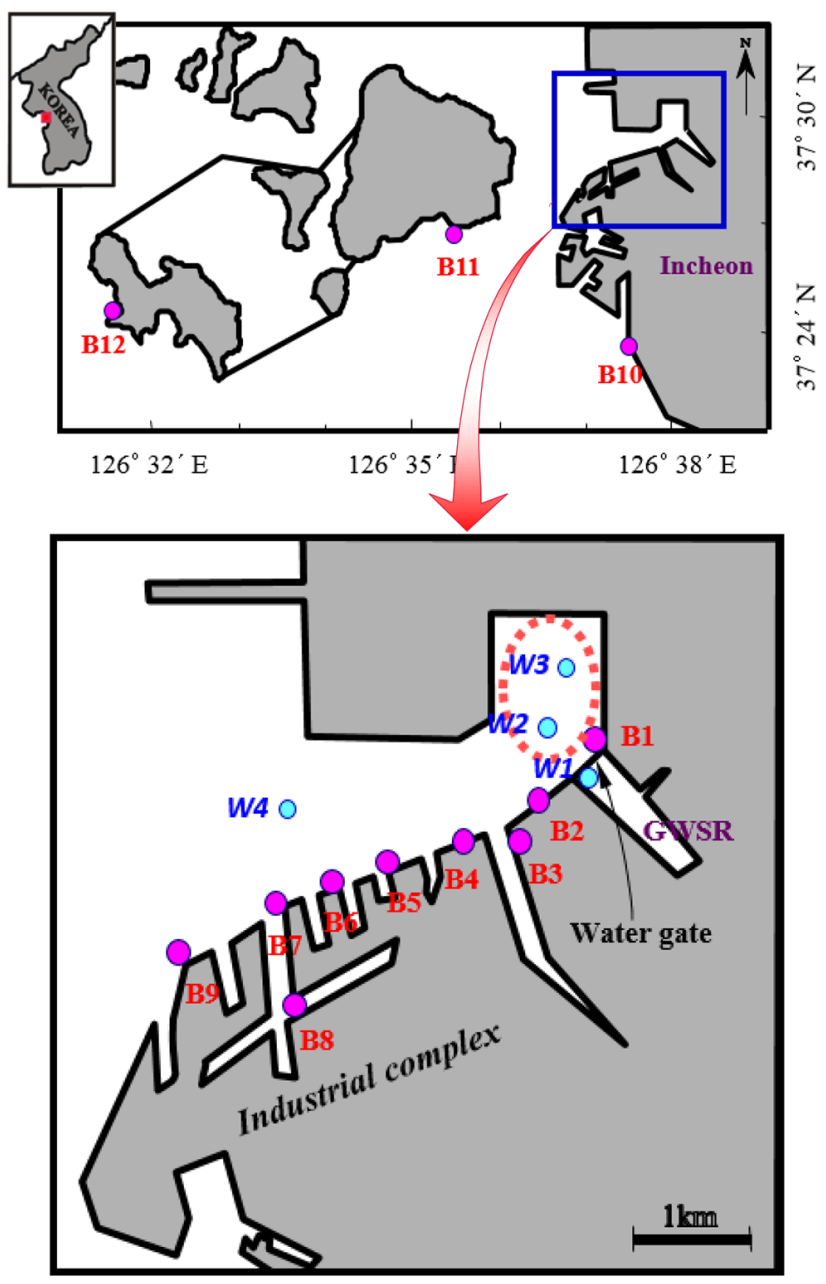

Fig. 1. Study area and sampling sites (oyster, B1-B12; water, W1-W4; crab and goby from dotted area around W2\&W3). Sampling sites are assigned to inner (W1-W3 and B1-B3) and outer parts (W4 and B4-B9) of the harbor and outside of the harbor as reference sites (B10-B12).

were used for analysis of oyster $(\mathrm{n}=25)$ and crab $(\mathrm{n}=20$ for male and $n=30$ for female). For two sizes of goby (12.9 \pm 0.5 $\mathrm{cm}, \mathrm{n}=7 ; 16.4 \pm 1.0 \mathrm{~cm}, \mathrm{n}=9$ ), we collected and analyzed muscle tissues.

\subsection{Chemical Analysis}

$15 \mathrm{~L}$ of water sample was filtered with pre-extracted glass-fiber filters $(0.7 \mu \mathrm{m})$. Dissolved water of every $1 \mathrm{~L}$ was extracted with $120 \mathrm{~mL}$ of methylene chloride (pesticide grade, Burdick \& Jackson) in $2 \mathrm{~L}$ glass funnel, to which surrogate standards were added. Extraction was repeated totally three times by shaking with KM shaker (Iwaki Sangyo Co., LTD., Japan) at $200 \mathrm{spm}$ for $10 \mathrm{~min}$. After combined, all of extracts were dried with anhydrous sodium sulfate and finally concentrated to $2 \mathrm{~mL}$ after solvent exchange with hexane.

The tissue samples (15 g) were ground with a Tekmar tissuemizer (Cincinnati, OH, USA) and extracted in a 200-mL glass tube. Both 
$50 \mathrm{~g}$ of sodium sulfate and $100 \mathrm{~mL}$ dichloromethane were then added to this tube. The extraction was repeated twice with fresh dichloromethane. Additional details regarding the extraction and cleanup procedures of biota and water samples and of gas chromatography are available elsewhere [10-12].

OCP measured in this study includes four group: Hexavchlorobenzene (HCBz), hexachlorocyclohexanes (HCHs; sum of alpha-, beta-, gamma-, and delta-isomers), chlorodanes (CHLs; sum of trans-chlordane (trans-CHL), cis-chlordane (cis-CHL), trans-nonachlor (trans-NCL), cis-nonachlor (cis-NCL), and heptachlor epoxide (HepEpox)), and DDTs (sum of o,p'-DDE, p,p'-DDE, o,p'-DDD, p,p'-DDD, o,p'-DDT, and p,p'-DDT).

Average recoveries of surrogate standards (4,4'-dibromooctafluorobiphenyl, PCB 103 and PCB 198), which were spiked into the samples before extraction, were $75 \%, 76 \%$, and $89 \%$, respectively, in dissolved phase; and $68 \%, 84 \%$, and $80 \%$, respectively, in biota. The method-detection limits were $0.33 \mathrm{pg} / \mathrm{L}$ to $1.25 \mathrm{pg} / \mathrm{L}$ in dissolved water and $0.03 \mathrm{ng} / \mathrm{g}$ to $0.99 \mathrm{ng} / \mathrm{g}$ in biota on a dry-weight basis. As standard reference materials, we used AEA 142/OC (International Atomic Energy Agency, Vienna, Austria) for biota. The analytical values varied within $\pm 35 \%$ of the true values. Mean relative standard deviations for standard reference material were $5.9 \%$. No target compounds were detected in procedural blanks which were run together with every 8 samples.

\subsection{Bioaccumulation Factor (BAF) and Trophic Transfer Factor (TTF)}

The trophic-level (TL) position for individual organisms can be determined using stable isotopes of nitrogen (i.e., increase in ${ }^{15} \mathrm{~N}$ from the diet to the consumer, $\delta^{15} \mathrm{~N}$ ) [13]. However, measurements of such stable isotopes was not available in this study and then trophic position of each biota group was arbitrarily assigned based on their nominal eating habits: Zooplankton as a primary consumer, oyster (in pelagic) and crab (in benthic) as a secondary consumer, and goby (in pelagic) as a top predator/consumer. Oyster and crab investigated in this study are known to ingest suspended organic materials such as zooplankton and detritus in water column and sessile organic materials (mainly microalgae, bacteria and detritus) on the surface of stones, respectively, as a food source [14]. On the other hand, goby as a carnivorous predator ingest zooplankton, lugworm, and small benthos.

Bioaccumulation phenomenon reflects the uptake of chemical via both respiration (i.e., passive diffusion between dissolved phase of water and cell of biota) and food intake (i.e., active advection) $[6,9]$. BAF (dimensionless or $\mathrm{L} / \mathrm{kg}$ ) is calculated as below.

$$
B A F=\frac{C_{\text {or ganism }}}{C_{D W}}
$$

where, $C_{\text {organism }}$ and $C_{D W}$ indicate lipid-normalized concentration of chemical in tissue of organism (unit; ng/kg-lw) and chemical concentration in dissolved phase of water (ng/L), respectively.

TTF can be used to determine biomagnification extent, which indicates the enrichment of chemical accumulated in higher trophic level relative to lower trophic level. So, TTF is calculated as below:

$$
T T F=\frac{C_{H L \_ \text {organism }}}{C_{\text {LL_organism }}}
$$

where, $C_{H L \_ \text {organism }}$ and $C_{L L \_ \text {organism }}$ indicate lipid-normalized concentration of chemical in relatively higher and lower level organisms (unit; ng/kg-lw), respectively. In the present study, body residue

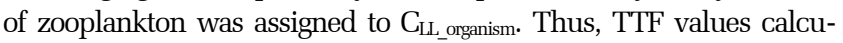
lated in this study indicate the biomagnification factors of OCPs at each trophic level (oyster, crab, or goby) against zooplankton.

\section{Results and Discussions}

\subsection{Concentration and Spatial Distribution of OCPs}

Water (sites W1 to W4) and oyster (site B1 to B9) were collected from inner part to outer part of the harbor to investigate the spatial distribution in OCP contamination. W1 is the site for the freshwater (i.e., wastewater) discharged from nearby industrial factories and W2 to W4 are the sites for seawater. Overall, all of OCPs showed the highest concentration in site-W1, indicating that GWSR plays a role of significant input source (Fig. 2(a)). Among three seawater samples, two inner sites showed clearly higher levels than outer site for HCBz (0.27 ng/L at W2 and $0.56 \mathrm{ng} / \mathrm{L}$ at W3 versus 0.06 $\mathrm{ng} / \mathrm{L}$ at $\mathrm{W} 4)$ and CHLs $(0.18 \mathrm{ng} / \mathrm{L}$ at $\mathrm{W} 2$ and $0.82 \mathrm{ng} / \mathrm{L}$ at $\mathrm{W} 3$ versus $0.06 \mathrm{ng} / \mathrm{L}$ at W4), while HCHs and DDTs exhibited relatively uniform distribution along the three sites $(2.48 \mathrm{ng} / \mathrm{L}$ at $\mathrm{W} 2,3.75$ $\mathrm{ng} / \mathrm{L}$ at $\mathrm{W} 3$, and $2.40 \mathrm{ng} / \mathrm{L}$ at $\mathrm{W} 4$ for HCHs and $0.07 \mathrm{ng} / \mathrm{L}$ at W2, $0.10 \mathrm{ng} / \mathrm{L}$ at $\mathrm{W} 3$, and $0.16 \mathrm{ng} / \mathrm{L}$ at $\mathrm{W} 4$ for DDTs).

Except for HCBz, spatial distribution pattern of OCPs body residue measured in oyster was similar with that in seawater (Fig. 2(b)). That is, lipid normalized concentration of CHLs (sum of $\mathrm{CHL}$ isomers) declined gradually from inner (190.4 $\pm 60.6 \mathrm{ng} / \mathrm{g}$ at B1-B3) to outer part (113.0 $\pm 61.8 \mathrm{ng} / \mathrm{g}$ at B4-B9) of the harbor and to reference sites outside the harbor $(34.3 \pm 8.55 \mathrm{ng} / \mathrm{g}$ at B10-B12). On the other hand, such a gradually decreasing trend was less clear for DDTs (479.5 $\pm 75.7 \mathrm{ng} / \mathrm{g}$ vs. $456.8 \pm 217.5 \mathrm{ng} / \mathrm{g}$ vs. $262.7 \pm 126.6 \mathrm{ng} / \mathrm{g}$, respectively) or reversal for HCHs (13.4 $\pm 5.5 \mathrm{ng} / \mathrm{g}$ vs. $22.3 \pm 6.9 \mathrm{ng} / \mathrm{g}$ vs. $35.1 \pm 5.7 \mathrm{ng} / \mathrm{g}$, respectively). It may be because HCBz in most ofoysters other than B8 and B10 were detected near the detection limit a that the spatial distribution of $\mathrm{HCBz}$ was not clear. Because of its water soluble and volatile properties compared with other OCPs, seawater current and/or atmospheric deposition might be more important contributor to its transport and distribution of HCHs. For example, substantial amounts of HCHs can be transported from Chinese rivers [15-17] or atmospheric deposition [18] into the Yellow sea and then current might move HCHs to the Korean peninsula. The greater HCHs level was observed in the Yellow Sea offshore than the East Sea offshore [19] and relatively uniform levels were found along the Korean coastal sediment or sedentary bivalves which was contrast to distributions of other OCPs [20, 21]. Differently from HCHs, CHLs and DDTs had shown the most polluted pattern around the harbor and population/industry-dense bays [21-23]. Relatively uniform distribution of DDTs in oyster might be due to ubiquitous sources including input from surrounding tributaries [10]. In short, OCPs in the study area seems to be influenced by different sources: 

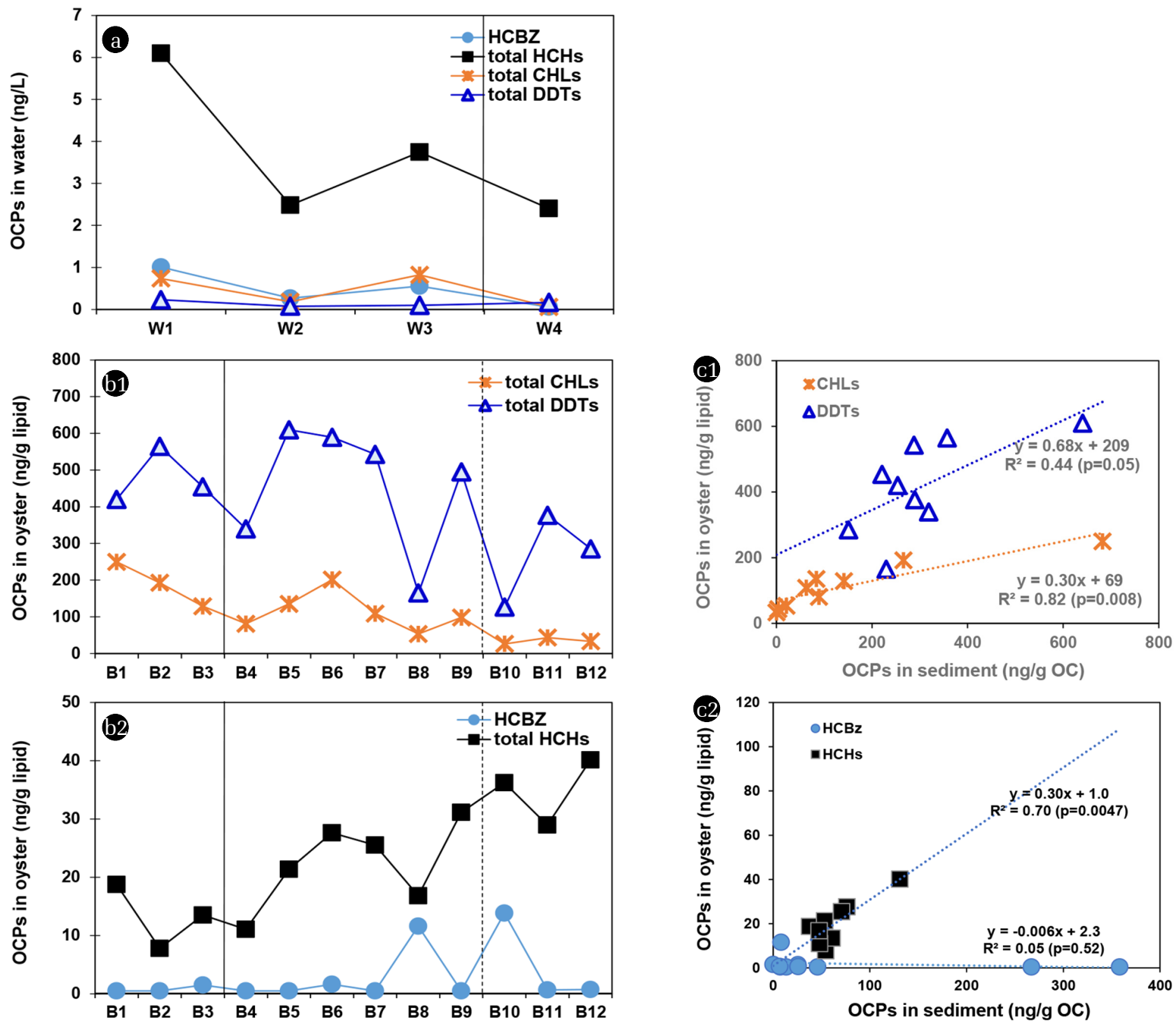

Fig. 2. Spatial distribution of OCPs in water (a) and oyster (b), and the relationship of OCPs levels between oyster and sediment (c) from study area. Sites at left-side of solid vertical lines in each panel (i.e., W1-W3 and B1-B3) indicate inner sites of the harbor, sites between solid and dotted lines (i.e., W4 and B4-B9) indicate outer sites of the harbor, and sites at the right-side of dotted line (i.e., B10-12) indicate reference sites. OCPs in sediment was cited from Kim et al. [10].

for example, strong input from GWSR for CHLs, several input sources for DDTs, and transport from outside of the harbor for HCHs.

A previous study reported the spatial distribution of OCPs in both subtidal and tidal surface sediment which had been collected in the same sampling time [10]. In the present study, we compared OCPs levels in oyster of this study with and those in tidal surface sediment of a previous study [10] since oyster has habitat in tidal zone. There were significant correlations in spatial distribution of CHLs, DDTs, and HCHs between surface sediment and oyster when their concentrations were normalized by organic carbon for sediment and lipid content for oyster (Fig. 2(c)). Both sediment and sedentary organisms (i.e., bivalve) has been used for mussel watch program since 1975 to define the spatial and temporal trends of environmental pollutants because both matrices tends to accumulate certain contaminants and thus to reflect their recent contamination status [24, 25]. Most studies for mussel watch pro- gram has based on nationwide monitoring [21-23] but there are very few studies to compare two monitoring matrices (i.e., sediment versus bivalve) within such a narrow harbor with this study. The finding of this study indicates that two monitoring matrices can be used complementarily for monitoring contamination, even at a narrow space scale.

\subsection{Trophic Transfer and Bioaccumulation of OCPs}

It is noticeable that although CHLs showed a gradual decreasing trend from inner to outer part of the harbor, the difference of average concentrations between inner (B1-B3) and outer sites (B4-B9) of the harbor were within two times as for all OCP groups. Furthermore, the composition patterns of isomers were very similar among the sites in the harbor (Fig. 3). This might be caused by strong tidal circulation in this area and so we can conclude that OCPs distributed homogeneously in space in the harbor. 

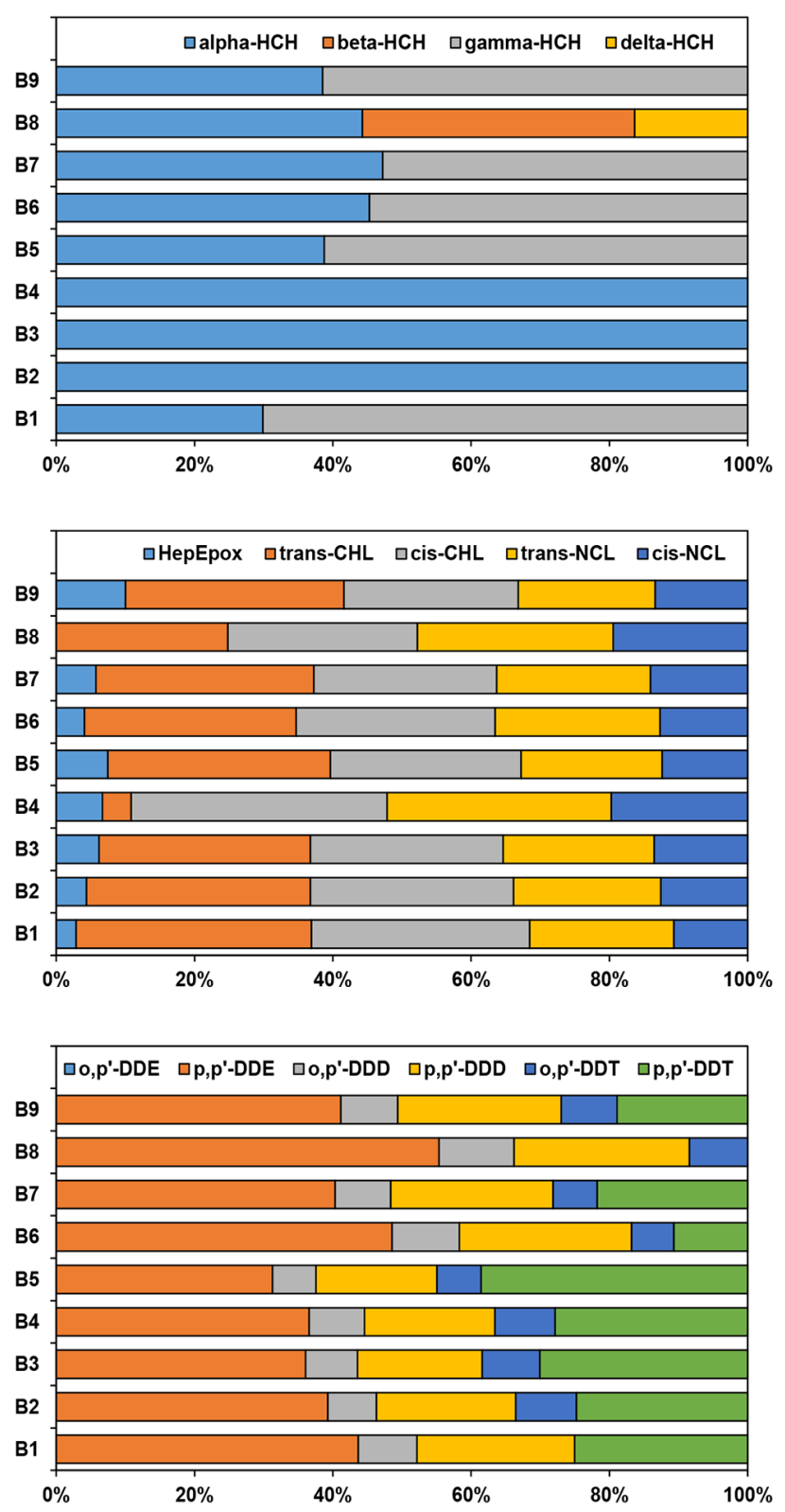

Fig. 3. Homogeneity of spatial distribution of OCP isomers.

Fig. 4 shows a brief picture of different trophic transfer and bioaccumulation extent of OCP groups in that dominant OCP changed along the trophic positions. HCHs was a predominant component in seawater (approximately 80\% of total OCPs) followed by CHLs, HCBZ, and DDTs. In zooplankton as a primary consumer, DDTs was the most prevalent but HCHs still accounted for $17 \%$ of total OCPs. However, relative composition of OCPs dramatically changed along different trophic positions, which showed an increasing trend for CHLs but decreasing trend for DDTs on higher trophic position. HCHs was a minor component of OCPs in organisms of higher trophic positions from secondary consumers (i.e., oyster) to top predator (i.e., goby), indicating non- or less bioaccumulativity of HCHs.

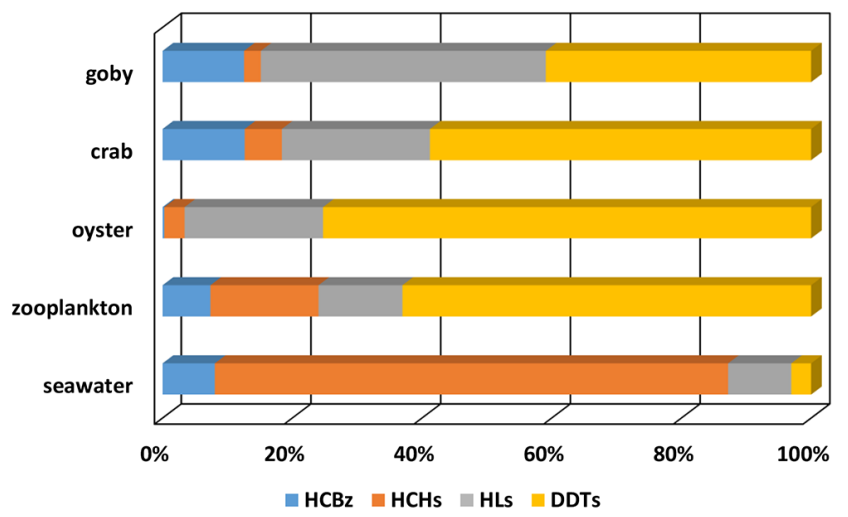

Fig. 4. Change of relative composition of OCPs in different trophic levels.

Further qualification of bioaccumulation, we compared OCP body residues in organisms of different trophic levels in Table 1 and Fig. 5 to 6. Compared with a female crab (pooled sample of $n=30$ ), a male crab (pooled sample of $n=20$ ) contained somewhat higher concentrations for HCBz, HCHs, and CHLs but similar level for DDTs. Of different two sized gobies, HCBz and CHLs were a little higher in smaller goby (pooled sample of $n$ = 7) but HCHs and DDTs were higher in larger goby (pooled sample of $n=9$ ) reversely. Difference of OCP levels were within two times between male and female of crab and between two size classes of goby. Barni et al. [26] observed no clear difference in POPs body residue between male and female of shallow lake fish species. Sex differences were found just for inorganic compounds such as arsenic and cadmium with higher in female crabs than in male crabs [27], as a possible cause of which the authors suggested the dilution by the faster growth of male crab. No influence of sex was observed in the body residue of flame retardant both Lake Trout and Walleye, while a reversal result about size effect existed for different fish species (a positive linear relationship for Lake Trout versus negative linear relationship for Walleye) [28]. Accumulation of pollutant occurs when total intake overpass total output through growth dilution, metabolism, fecal egestion, and egg egestion (for female only). As for less- or non-metabolized pollutants such as POPs, a slow growth can cause an increasing body residue with age in male and a regular reproduction can alleviate a body residue in female [29]. In real environment, the effect of sex and size on bioaccumulation of pollutants can be more complicated because of temporal and spatial variation in physiological condition, food chain, and exposure concentration, and/or their co-variation. Gweurtz et al. [30] detected the significant differences between fish sexes in less than $25 \%$ of the tests conducted for mercury/total-PCBs. A pooled sample for each size and each sex in our study did not allow further statistical analysis. However, observed narrow difference and inconsistent trend with different OCP compounds was consistent with the results of other field studies mentioned above. Thus, sex or size effect was ignored in trophic transfer calculation since their effects could not be defined clearly.

In all calculation for BAF and TTF, the mean concentrations of seawater (W2 to W4), zooplankton (W2 and W4), oyster 
Table 1. Concentrations of OCPs in Seawater and Marine Organisms Used to Calculate BAF and TTF

\begin{tabular}{|c|c|c|c|c|c|}
\hline & Seawater (ng/L) & Zooplankton (ng/g lw) & Oyster (ng/g lw) & Crab (ng/g lw) & Goby (ng/g lw) \\
\hline $\mathrm{HCBz}$ & $0.29 \pm 0.25$ & $21.62 \pm 3.80$ & $1.64 \pm 3.80$ & $99.17 \pm 35.73$ & $148.24 \pm 20.04$ \\
\hline $\mathrm{HCHs}$ & $2.88 \pm 0.75$ & $48.87 \pm 13.26$ & $19.29 \pm 13.91$ & $44.88 \pm 26.49$ & $30.57 \pm 10.19$ \\
\hline alpha-HCH & $0.54 \pm 0.14$ & $12.10 \pm 4.14$ & $10.03 \pm 2.77$ & $2.75 \pm 3.89$ & $<\mathrm{MDL}$ \\
\hline beta-HCH & $1.02 \pm 0.12$ & $23.36 \pm 5.87$ & $0.74 \pm 2.21$ & $41.28 \pm 23.82$ & $18.52 \pm 5.89$ \\
\hline gamma-HCH & $1.19 \pm 0.82$ & $9.23 \pm 1.87$ & $8.22 \pm 8.01$ & $<\mathrm{MDL}$ & $12.06 \pm 4.30$ \\
\hline delta-HCH & $0.13 \pm 0.12$ & $4.19 \pm 1.39$ & $0.31 \pm 0.92$ & $0.86 \pm 1.21$ & $<\mathrm{MDL}$ \\
\hline CHLs & $0.35 \pm 0.41$ & $37.94 \pm 13.79$ & $131.77 \pm 62.24$ & $178.78 \pm 79.49$ & $518.76 \pm 124.72$ \\
\hline trans-CHL & $0.11 \pm 0.11$ & $11.65 \pm 3.76$ & $41.56 \pm 25.40$ & $16.08 \pm 5.13$ & $56.83 \pm 22.13$ \\
\hline cis-CHL & $0.16 \pm 0.17$ & $11.83 \pm 4.49$ & $40.52 \pm 20.07$ & $12.54 \pm 0.84$ & $137.55 \pm 45.31$ \\
\hline trans-NCL & $0.08 \pm 0.13$ & $9.00 \pm 3.66$ & $31.34 \pm 12.81$ & $109.43 \pm 66.00$ & $230.71 \pm 38.20$ \\
\hline cis-NCL & $<\mathrm{MDL}$ & $5.45 \pm 1.88$ & $18.36 \pm 5.72$ & $40.73 \pm 19.45$ & $93.67 \pm 19.08$ \\
\hline DDTs & $0.11 \pm 0.05$ & $184.75 \pm 73.40$ & $464.36 \pm 141.91$ & $460.38 \pm 3.14$ & $482.68 \pm 32.08$ \\
\hline o,p'-DDE & $<\mathrm{MDL}$ & $<\mathrm{MDL}$ & $<\mathrm{MDL}$ & $<\mathrm{MDL}$ & $<\mathrm{MDL}$ \\
\hline p,p'-DDE & $0.06 \pm 0.05$ & $71.35 \pm 30.49$ & $187.11 \pm 57.00$ & $279.44 \pm 31.37$ & $335.98 \pm 31.47$ \\
\hline o,p'-DDD & $<\mathrm{MDL}$ & $22.09 \pm 6.21$ & $37.16 \pm 10.94$ & $15.94 \pm 2.97$ & $0.00 \pm 0.00$ \\
\hline p,p'-DDD & $0.02 \pm 0.03$ & $48.20 \pm 15.98$ & $99.45 \pm 32.57$ & $43.08 \pm 6.59$ & $45.08 \pm 0.40$ \\
\hline o,p'-DDT & $0.03 \pm 0.04$ & $<\mathrm{MDL}$ & $31.17 \pm 15.12$ & $69.14 \pm 7.61$ & $<\mathrm{MDL}$ \\
\hline p,p'-DDT & $<\mathrm{MDL}$ & $43.11 \pm 20.71$ & $109.47 \pm 63.37$ & $52.78 \pm 11.06$ & $101.62 \pm 0.22$ \\
\hline
\end{tabular}

$\mathrm{HCH}$ is the sum of concentrations of four $\mathrm{HCH}$ isomers CHLs is the sum of concentrations of four CHL isomers DDTs is the sum of concentrations of six DDT isomers
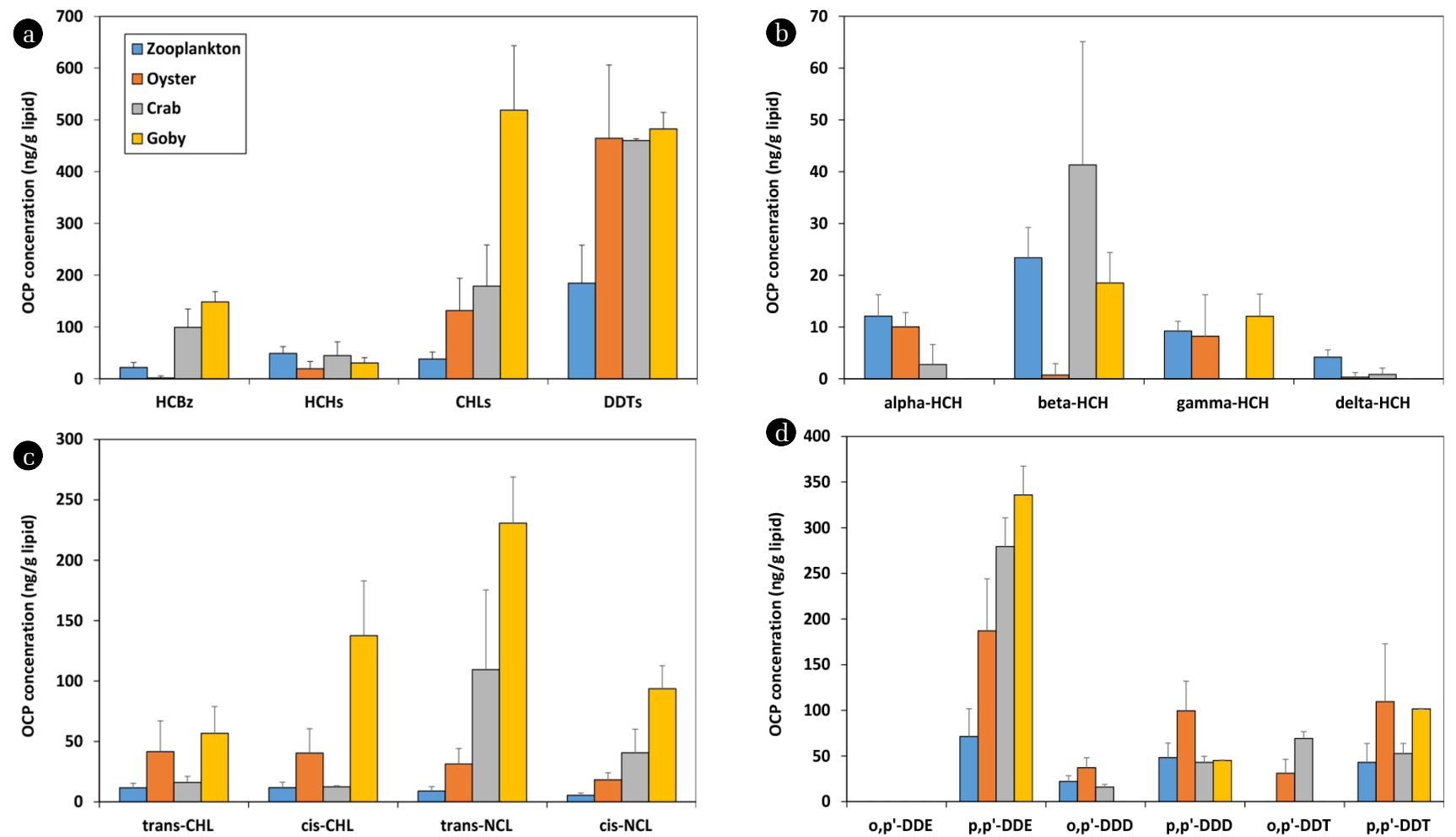

Fig. 5. Comparison of bioaccumulation extent among OCP groups (a) or isomers (b), (c), and (d). 
(B1 to B9), crab (male and female), and goby (muscle tissues of different two sized fishes) were used assuming that homogeneity in concentration distribution was established in the whole harbor area as discussed earlier.

Three OCP groups (i.e., HCBz, CHLs, and DDTs) exhibited a dramatic accumulation along the trophic level from zooplankton to goby (Table 1 and Fig. 5). Similar bioaccumulation was observed for most of individual isomers of CHLs and DDTs. However, such a trend was unclear for HCHs. Particularly, HCHs did not show any accumulation trend through trophic level and the relatively low level of alpha-HCH were found in the higher trophic level. Bioaccumulation extent is controlled by both hydrophobic (or lipophilic) potentials, which is represented by organism-water partition coefficient (i.e., BAF or $\mathrm{K}_{\mathrm{OW}}$ as a surrogate of BAF), and metabolism in body [6, 9]. Normally, OCPs are known to be persistent and thus difficult to be metabolized. So, hydrophobic potential could be a major factor to control their bioaccumulation. The target OCPs show a wide range of $\mathrm{K}_{\mathrm{OW}}$ value from $10^{3.72}$ (for $\mathrm{HCHs}$ ) to $10^{6.91}$ (p,p'-DDT). HCHs have the lowest $\mathrm{K}_{\mathrm{Ow}}$ values among target OCPs in this study (log Kow of 3.72 to 4.14). Therefore, we can infer that the bioaccumulation or trophic transfer of HCHs is less significant than other OCPs with greater $\mathrm{K}_{\mathrm{OW}}$ values.

The dependency of BAF and TTF on Kow was further investigated in Fig. 6. Overall, a good linear correlation was established between measured $\log \mathrm{BAF}$ and $\log \mathrm{K}_{\mathrm{Ow}}$. This means that $\mathrm{K}_{\mathrm{OW}}$ values can be a good surrogate for bioaccumulation extent of OCPs within at least a range of $\log \mathrm{K}_{\mathrm{OW}}$ of 3.72-6.91. However, it is noticeable that most of BAF values from the goby, nominally the highest trophic level, positioned over the 1:1 line of log BAF and log $\mathrm{K}_{\mathrm{OW}}$ while those from the lower trophic levels (particularly, zooplankton and oyster) were in lower zone below the 1:1 line (Fig. 6(a)). This indicates that the greater fugacities could be established in the higher trophic level. Therefore, biomagnification via food intake might occur in higher trophic levels.

TTF values, representing enrichment relative to zooplankton along food-chain, were similar among two secondary consumers (oyster and crab) and even some OCPs with log $\mathrm{K}_{\mathrm{OW}}$ below 5 did not show any enrichment (Fig. 6(b)). As for goby which is arbitrarily assigned to the highest trophic position (i.e., top predator), $\log$ TTF values of most hydrophobic OCPs ( $>5$ of $\log \mathrm{K}_{\mathrm{OW}}$ ) ranged from 0.5 to 1.5 of log unit; that is, these OCPs were magnified by over 3 to 30 times relative to zooplankton. When $\mathrm{C}_{\mathrm{LL} \_ \text {organism }}$ in Eq. (2) is assigned to oyster or crab, TTF values indicate the biomagnification factors (BMFs) of OCPs from oyster or crab to goby. The TTF values ranged from 1.04 (DDTs) to 90 (HCBz) for oyster-to-goby and from 0.68 (HCHs) to 2.9 (CHLs) for crab-to-goby.

In this study, it was not possible to clarify the prey-predator relationship because stable isotope ratio or gut content were not analyzed and thus it is limited in explaining the biomagnification extent of target OCPs from prey to predator. Nevertheless, the plot of BAF and TTF values observed in this study against $\mathrm{K}_{\mathrm{OW}}$ confirmed the occurrence of biomagnification with increasing trophic level, although the nominal trophic positions based on their main food source were used. So, nominal trophic levels assigned in this study seem reasonable though it is not perfect for prey-predator relationship. TTF values based on nominal trophic level are not exactly the same as BMFs which is based on the accurate
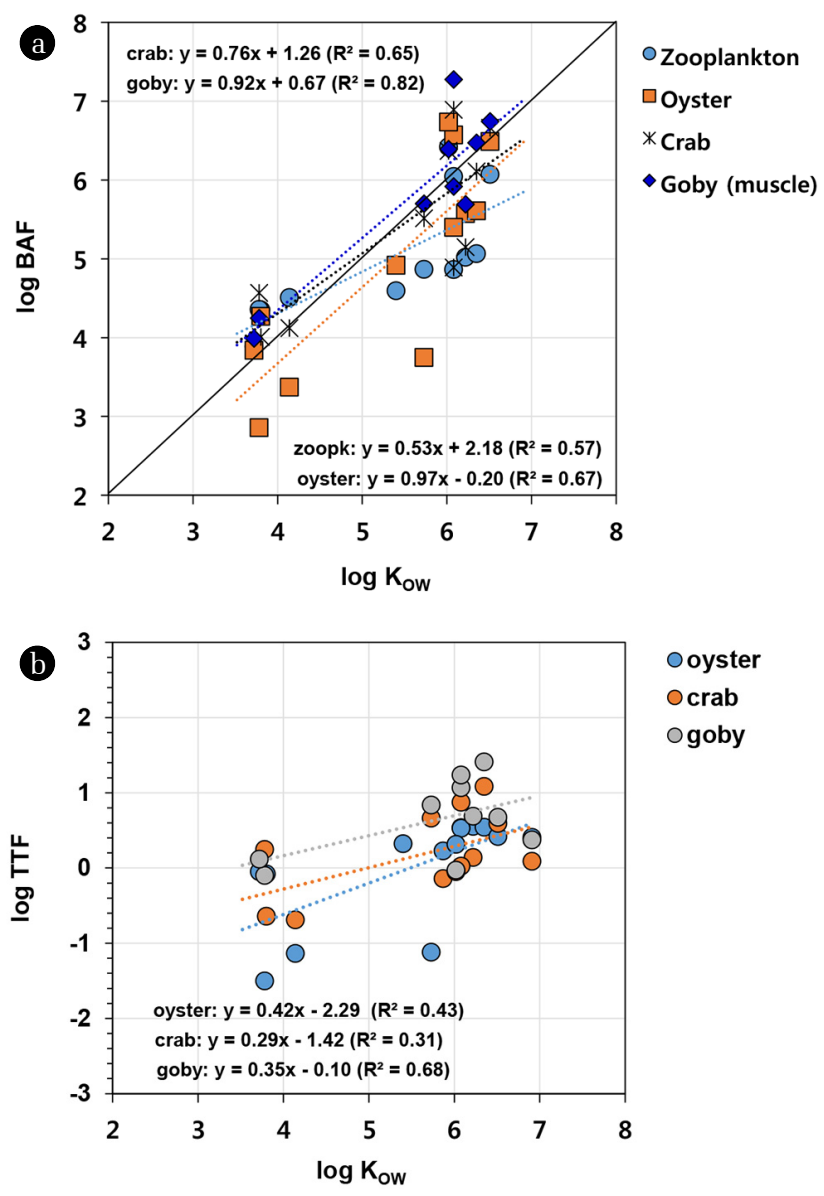

Ooyster

Ocrab

Ogoby

Fig. 6. Bioaccumulation factor (BAF) (a) and trophic transfer factor (TTF) (b) as a function of octanol-water partition coefficient (log Kow). All TTF values were calculated against zooplankton.

prey-predator relationship. However, TTF values can be used as an alternative metric for BMFs, in cases that ecosystem-specific prey-predator relationships were not known.

Laboratory-based test results have been conventionally used in establishing water quality criteria since it is not possible to test biomagnifcation extent through food-web in the laboratory condition. Such a laboratory-based bioaccumulation can represent BCF which reflect the intake via respiration only. When based on TTF measured in this study, more hydrophobic OCPs with $\log \mathrm{K}_{\mathrm{Ow}}>5$ were enriched by several to several ten times in the highest trophic level relative to the lowest trophic level. This means that water quality criteria originated from BCF (assuming that BCF is calculated from zooplankton and water) cannot protect the predators (goby in this study) in the higher trophic position. Thus, biomagnification factor (TTF in this study), which can be improved by accurate assessment of prey-predator relationship using stable isotope analysis, should be considered in the establishment of water quality criteria.

Another one to be discussed is that the slopes of log TTF (or $\log$ BAF) against log $K_{\mathrm{OW}}$ were not significantly different among trophic levels. This means that more hydrophobic chemicals did 
not more magnify at least for OCPs with the range of maximum 7 of $\log \mathrm{K}_{\mathrm{Ow}}$. This finding supports that it might take longer times for more hydrophobic chemicals to reach equilibrium or to overpass the equilibrium because the penetration across cell of more hydrophobic chemicals with bigger molecular size can be limited. Thus, biomagnification extent as a function of $\mathrm{K}_{\mathrm{OW}}$ could appear less obvious for more hydrophobic pollutants in a real environment if life span of organism is not long enough to overcome the hindrance of cell penetration.

\section{Conclusions}

The present study was designed to characterize the bioaccumulation of OCPs in marine organisms (zooplankton, oyster, crab, and goby) on different trophic level. In the present study, sedentary bivalve (oyster) showed strong correlations in OCPs levels with surface sediment in study area. This indicates the two compartments can be used complementarily for pollution monitoring of OCPs even in narrow scale in space. Four OCP groups showed dramatic change in relative composition profile along the trophic positions; for instance, relative enrichment of CHLs were the greatest with increasing trophic position while HCHs did not any bioaccumulative feature. Although nominal trophic position was arbitrarily applied, most of BAF values from higher trophic level positioned over the 1:1 line of log BAF and log Kow while those from lower trophic levels were in lower zone below the 1:1 line, indicating the greater fugacity in the higher trophic level and thus the occurrence of biomagnification via ingestion. TTF values investigated in this study showed that more hydrophobic OCPs with log $\mathrm{K}_{\mathrm{OW}}>5$ were enriched by several to several ten times in top predator (goby) of the study area.

\section{Acknowledgments}

This work was supported by Incheon National University Research Grant in 2014.

\section{References}

1. Stockholm Convention on Persistent Organic Pollutants. UNEP: Persistent organic pollutants 2001. Available from: http://www. pops.int/.

2. Kim SK, Khim JS, Lee KT, Giesy JP, Kannan K, Lee DS. Chapter 2. Emission, contamination and exposure, fate and transport, and national management strategy of persistent organic pollutants in South Korea. In: Li A, Tanabe S, Jiang G, Giesy JP, LamPKS, eds. Developments in Environmental Sciences. New York: Elsevier Ltd.; 2007. p. 31-157.

3. Environment Canada. Guidance manual for the categorization of organic and inorganic substances on Canada's Domestic Substances List. Existing Substances Branch, Environment Canada, Otttawa, Ont., Canada; 2003. p. 125.

4. Borgå K, Kidd KA, Muir DCG, et al. Trophic magnification factors: Considerations of ecology, ecosystems, and study design. Integr. Environ. Assess. Manag. 2012;8:64-84.

5. Burkhard LP, Borgå K, Powell DE, et al. Improving the quality and scientific understanding of trophic magnification factors (TMFs). Environ. Sci. Technol. 2013;47:1186-1187.

6. Gobas FAPC, de Wolf W, Buckhard LP, Verbruggen E, Plotzke K. Revisiting bioaccumulation criteria for POPs and PBT assessments. Integr. Environ. Assess. Manag. 2009;5:624-637.

7. Gobas FAPC, Xu S, Kozerski G, et al. Fugacity and activity analysis of the bioaccumulation and environmental risks of decamethylcyclopentasiloxane (D5). Environ. Toxicol. Chem. 2015;34:2723-2731.

8. Gobas FA, Morrison HA. Bioconcentration and biomagnification in the aquatic environment. In: Boethling RS, Mackay D, eds. Handbook of property estimation methods for chemicals, environmental and health sciences. Boca Raton (FL): CRC; 2000. p. 189-231.

9. Arnot JA, Gobas FAPC. A review of bioconcentration factor (BCF) and bioaccumulation factor (BAF) assessments for organic chemicals in aquatic organisms. Environ. Rev. 2006;14: 257-297.

10. Kim SK, Kang DJ, Kim KR, Lee DS. Distribution of organochlorine pesticides in intertidal and subtidal sediments in coastal wetland with high tidal ranges. Arch. Environ. Contam. Toxicol. 2010;58:514-522.

11. Kim SK, Lee DS, Oh JR, Kahng SH. Effects of extreme tidal range on characteristics of polychlorinated biphenyl distribution in sediment of industrial Incheon North Harbor, Korea. Environ. Toxicol. Chem. 2000;19:2448-2456.

12. Kim S-K, Lee DS, Oh JR. Characteristics of trophic transfer of polychlorinated biphenyls in marine organisms in Incheon North Harbor, Korea. Environ. Toxicol. Chem. 2002;21:834-841.

13. Fisk AT, Hobson KA, Norstrom RJ. Influence of chemical and biological factors on trophic transfer of persistent organic pollutants in the north water polynya marine food web. Environ. Sci. Technol. 2001;35:732-738.

14. Kurihara Y, Okamoto K. Cannibalism in a grapsid crab, Hemigrapsus penicillatus. Mar. Ecol. Prog. Ser. 1987;41:123-127.

15. Tang Z, Yang Z, Shen Z, Niu J, Cai Y. Residues of organochlorine pesticides in water and suspended particulate matter from the Yangtze River catchment of Wuhan, China. Environ. Monit. Assess. 2008;137:427-439.

16. Tan L, He M, Men B, Lin C. Distribution and sources of organochlorine pesticides in water and sediments from Daliao River estuary of Liaodong bay, Bohai Sea (China). Estuar. Coast. Shelf Sci. 2009;84:119-127.

17. Liu M, Cheng S, Ou D, et al. Organochlorine pesticides in surface sediments and suspended particulate matters from the Yangtze estuary, China. Environ. Pollut. 2008;156:168-173.

18. Tian C, Ma J, Liu L, Jia H, Xu D, Li Y-F. A modeling assessment of association between East Asian summer monsoon and fate/outflow of a-HCH in Northeast Asia. Atmos. Environ. 2009;43:3891-3901.

19. Won JH, Hong SH, Shim WJ, Yim UH, Kim GB. Persistent organochlorine pollutants in Korean offshore waters: Squid (Todarodes pacificus) as a biomonitor. Mar. Pollut. Bull. 2009;58:1229-1244. 
20. Lee KT, Tanabe S, Koh CH. Distribution of organochlorine pesticides in sediments from Kyeonggi Bay and nearby areas, Korea. Environ. Pollut. 2001;114:207-213.

21. Kim SK, Oh JR, Shim WJ, et al. Geographical distribution and accumulation features of organochlorine residues in bivalves from coastal areas of South Korea. Mar. Pollut. Bull. 2002;45:268-279.

22. Choi HG, Moon HB, Choi M, Yu J, Kim SS. Mussel watch program for organic contaminants along the Korean coast, 2001-2007. Environ. Monit. Assess. 2010;169:473-485.

23. Choi HG, Moon HB, Choi M, Yu J. Monitoring of organic contaminants in sediments from the Korean coast: Spatial distribution and temporal trends (2001-2007). Mar. Pollut. Bull. 2011;62:1352-1361.

24. Goldberg ED. The mussel watch: A first step in global marine monitoring. Mar. Pollut. Bull. 1975;38:170-181.

25. Kimbrough KL, Johnson WE, Lauenstein GG, Christensen JD, Apeti DA. An assessment of two decades of contaminant monitoring in the Nation's coastal zone. NOAA Technical
Memorandum NOS NCCOS 74. Silver Spring, MD; 2008.

26. Barni MFS, Ondarza PM, Gonzalez M, et al. Persistent organic pollutants (POPs) in fish with different feeding habits inhabiting a shallow lake ecosystem. Sci. Total Environ. 2016;550:900-909.

27. Julshamn K, Valdersnes S, Duinker A, Nedreaas K, Sundet JH, Maage A. Heavy metals and POPs in red king crab from the Barents Sea. Food Chem. 2015;167:409-417.

28. Su G, Letcher RJ, McGoldrick DJ, Backus SM. Halogenated flame retardants in predator and prey fish from the Laurentian Great Lakes: Age-dependent accumulation and trophic transfer. Environ. Sci. Technol. 2017;51:8432-8441.

29. Weijs L, Yang RSH, Covaci A, Das K, Blust R. Physiologically based pharmacokinetic (PBPK) models for lifetime exposure to PCB 153 in male and female harbor porpoises (Phocoena phocoena): Model development and evaluation. Environ. Sci. Technol. 2010;44:7023-7030.

30. Gweurtz SB, Bhavsar SP, Fletcher R. Influence of fish size and sex on mercury/PCB concentration: Importance for fish consumption advisories. Environ. Int. 2011;37:425-434. 